\title{
Research on the Impact of Industrial Development on Energy Utilization Efficiency under the Background of Urban Agglomeration Planning
}

\author{
Yuan Zheng ${ }^{1}$, Bo Yue ${ }^{1}$, Xuesong Han ${ }^{1, *}$, and Zheng $\mathrm{Li}^{1}$ \\ ${ }^{1}$ National Territory and Spatial Planning Research Institute of Sichuan Province, Chengdu, Sichuan, China
}

\begin{abstract}
At present, the trend of central cities leading the development of urban agglomerations and urban agglomerations driving regional development is becoming more and more significant. Based on the panel data of 16 cities in the Chengdu-Chongqing urban agglomeration from 2010 to 2015, this paper uses a fixedeffect model to study the relationship between industrial development and energy efficiency in urban agglomerations, central cities, and surrounding cities. The empirical results show that for the overall urban agglomerations, central cities and surrounding cities, the scale of the secondary industry has a negative correlation with energy consumption per unit of GDP. Industrial development will increase the total energy consumption, but it also contributes to energy efficiency. In order to achieve the goal of "carbon peak and carbon neutrality", cities must find a balance in development and seek ecological protection during development.
\end{abstract}

\section{Introduction}

With the increasing impact of greenhouse gases on the global environment, my country will increase its national independent contribution, adopt more powerful policies and measures, strive to reach the peak of carbon dioxide emissions by 2030 , and strive to achieve carbon neutrality by 2060. At the Central Economic Work Conference in December 2020, it was once again emphasized that "doing a good job in carbon peaking and carbon neutrality" will be one of the eight key tasks in 2021. In 2021, the "Carbon Peak and Carbon Neutrality" of the National Two Sessions was included in the government work report for the first time.

Urban agglomerations are usually urban economic development to a certain stage, with one or more central cities as the core, relying on a developed infrastructure network to form a form of spatial organization that transcends the administrative division model. ${ }^{[1]}$ On November 18, 2018, the Central Committee of the Communist Party of China and the State Council issued the "Opinions on Establishing a More Effective New Mechanism for Regional Coordination and Development", which clearly pointed out. The Beijing-Tianjin-Hebei urban agglomeration, the Yangtze River Delta urban agglomeration, the Guangdong-Hong Kong-Macao Greater Bay Area, the Chengdu-Chongqing urban agglomeration, the Yangtze River midstream urban agglomeration, the Central Plains urban agglomeration, the Guanzhong Plain urban agglomeration and other urban agglomerations promote the strategic integration and development of major national regions, and establish a center Cities lead the development of urban agglomerations, and urban agglomerations drive new models of regional development, and promote the integrated development of regional sectors.

The development of cities in the form of urban agglomerations is an important trend for my country's future social development. Improving energy efficiency is an important means to achieve the goal of "carbon peak and carbon neutrality". This article intends to explore the relationship between industrial development and energy efficiency. It is expected to provide a reference for the development of urban industries in the new era.

\section{The principle of the influence of urban agglomeration industry development on energy utilization efficiency}

The impact of urban agglomeration industry development on energy efficiency is mainly reflected in the following aspects.

\subsection{Improve energy efficiency through the division of labor within the urban agglomeration}

The company separates the businesses that they are not good at and consumes more energy within the urban agglomeration and outsources them to professional and efficient production service companies. Manufacturing companies can focus capital and management resources more on key areas and advantageous links, optimize resource allocation, concentrate on cultivating and

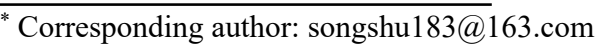


improving their core competitiveness, thereby improving energy efficiency.

\subsection{Improve energy efficiency through technological innovation}

Technological innovation can improve energy efficiency. This is because the productive service industry is highly knowledge-intensive and technology-intensive, and they can continuously input the knowledge, information and human resources needed for corporate innovation to the manufacturing companies to promote the occurrence of technological innovation and the transfer and diffusion of technology, To accelerate the upgrading of energy-saving equipment and clean technology, thereby improving energy efficiency.

\subsection{Large-scale production reduces energy consumption per unit product}

The inner space of the urban agglomeration is vast, which can accommodate more enterprises. The collaborative production between enterprises within the urban agglomeration can form large-scale benefits, thereby promoting enterprises to become bigger and stronger. Industrial development produces technological space overflow, unit product cost reduction and production factors flow, which brings economic development and scale improvement, and contributes to the improvement of energy utilization efficiency ${ }^{[1]}$.

\section{Model construction}

\section{1 research sample}

With the "Chengyu Economic Zone Regional Planning" approved by the State Council in 2011 and the "Chengyu Urban Agglomeration Development Plan" approved in 2016, the new urbanization trend in Chengdu-Chongqing area is obvious, and the industrial scale is increasing rapidly, which is comparable to other domestic urban agglomerations. With reference to the "Chengyu Economic Zone Regional Planning" and "Chengyu Urban Agglomeration Development Plan", this article uses Chengdu, Deyang, Mianyang, Nanchong, Dazhou, Guang'an, Suining, Ziyang, Meishan, Neijiang, Zigong, Luzhou, Yibin, Ya'an, Leshan, and Chongqing as the samples for the study.

\subsection{Model setting}

Based on the principle analysis of the impact of urban agglomeration industry development on energy utilization efficiency, we assume that the industrial development of urban agglomerations can improve the energy utilization efficiency in the region, but there is still uncertainty. In order to verify this hypothesis, an empirical test is needed, and the regression equation is set as follows:

$$
E_{i t}=\alpha_{0}+\beta_{1} I_{i t}+\beta_{2} X_{i t}+\mu_{i t}
$$

In Equation 1, E_it represents the explained variable, that is, energy consumption per unit of GDP, I_it represents the core explanatory variable, which represents the scale of the secondary industry, $\mathrm{X}$ it represents the control variable, $\mu$ it represents random disturbance, $i$ represents the city, and t represents time. Since the urban agglomeration presents the area where the central city leads the development of the urban agglomeration, the central city and the surrounding cities are distinguished in the measurement test and brought into the model test respectively.

\subsection{Variable description}

\subsubsection{Explained variable}

Energy consumption per unit of GDP (E) is the energy consumption of the regional GDP. Energy consumption is converted to standard coal for various energy sources. GDP is converted to comparable prices in 2010 according to the regional GDP index.

\subsection{Core explanatory variables}

The scale of the secondary industry (I) is the regional GDP of the secondary industry, converted into comparable prices in 2010 according to the regional GDP index.

\subsubsection{Control variable}

Combining relevant research, select the degree of industrial agglomeration, industrial structure ${ }^{[2-3]}$, and indirect related government intervention ${ }^{[4]}$, human capital and innovation level ${ }^{[5]}$ directly related to industrial development as control variables.

(1) The degree of industrial agglomeration (D): Using Shang Yongzhen et al. (2020) to calculate the division of labor index method in urban agglomerations ${ }^{[6]}$, the calculation formula is:

$$
D_{i t}=\frac{N_{i t} / N_{i S}}{N_{t} / N_{S}}
$$

In the formula, $N_{i t}$ represents the number of employment in the tertiary industry of the city i. $N_{i s}$ represents the number of employment in the secondary industry of the city i. $N_{t}$ represents the number of employment in the tertiary industry of the urban agglomeration, and $N_{s}$ represents the number of employment in the secondary industry of the urban agglomeration.

(2) Industrial structure (C): Select the proportion of employment in the secondary industry to the total employment.

(3) Government intervention (G): Select the proportion of fiscal expenditure to the regional GDP to measure.

(4) Human capital $(\mathrm{H})$ : Select the proportion of education expenditure to fiscal expenditure to measure. 
(5) Innovation level (S): Select the proportion of science and technology expenditure in fiscal expenditure to measure.

\subsubsection{Data Sources}

This paper selects the original samples of 15 cities in Chengdu, Deyang, Mianyang, Nanchong, Dazhou, Guang'an, Suining, Ziyang, Meishan, Neijiang, Zigong, Luzhou, Yibin, Ya'an, and Leshan in Sichuan Province, and a total of 16 cities in Chongqing from 2010 to 2015. According to the data, Chengdu and Chongqing are central cities, and the remaining 14 cities are neighboring cities. The data comes from the "Sichuan Statistical Yearbook" (2011-2016) and the "Chongqing Statistical Yearbook" (2011-2016).

\section{Empirical test analysis}

\subsection{Regression result}

\subsubsection{Hausman test}

The purpose of the Hausman test (Hausman and Taylor 1981) ${ }^{[7-8]}$ is to determine the correlation between individual effects and explanatory variables, and then to determine the choice of fixed effects mode or random effects mode. In this study, the plm software package of $\mathrm{R}$ language was used for Hausman test. Since the data may have autocorrelation and heteroscedasticity problems, an improved robust Hausman test can be used.

Table 1. Hausman Test Result Data Sheet

\begin{tabular}{|c|c|}
\hline method & p-value \\
\hline Hausman and Taylor Method & 0.01092 \\
\hline Improved robust Hausman test & $6.709 \mathrm{e}-05$ \\
\hline
\end{tabular}

Table 1 shows that the $\mathrm{P}$ value of the two test methods is less than 0.05 , so the null hypothesis is rejected at the $5 \%$ level and the fixed effects model is adopted.

\subsubsection{The impact of core explanatory variables on energy efficiency}

Table 2. Core explanatory variable fixed effect regression index table

\begin{tabular}{|c|c|c|c|}
\hline variable & $\begin{array}{c}\text { Urban } \\
\text { agglomeration }\end{array}$ & central city & Nearby Cities \\
\hline I & $\begin{array}{c}-0.152795 * * * \\
(0.022346)\end{array}$ & $\begin{array}{c}-0.101309 * * * \\
(0.014695)\end{array}$ & $\begin{array}{c}-0.72960 * * * \\
(0.03754)\end{array}$ \\
\hline \multicolumn{2}{|c|}{} & & \\
\hline
\end{tabular}

Note: *** means $\mathrm{p}<0.01, * *$ means $\mathrm{p}<0.05,{ }^{*}$ means $\mathrm{p}<0.1$, standard error in parentheses

First, perform a fixed-effect model regression on the core explanatory variables. Table 2 shows that for the entire urban agglomeration, central cities and surrounding cities, the impact coefficient of the secondary industry scale on unit GDP energy consumption is significantly negative at the $1 \%$ level.

Table 3. Econometric regression results

\begin{tabular}{|c|c|c|c|}
\hline variable & $\begin{array}{c}\text { Urban } \\
\text { agglomeration }\end{array}$ & central city & Nearby Cities \\
\hline I & $\begin{array}{c}-0.130824 * * * \\
(0.020222)\end{array}$ & $\begin{array}{c}-0.094709^{* *} \\
(0.027859)\end{array}$ & $\begin{array}{c}-0.691588 * * * \\
(0.047943)\end{array}$ \\
\hline $\mathrm{D}$ & $\begin{array}{c}-0.247681 * * * \\
(0.084463)\end{array}$ & $\begin{array}{c}0.511324 \\
(0.791668)\end{array}$ & $\begin{array}{l}-0.089489^{*} \\
(0.051790)\end{array}$ \\
\hline $\mathrm{C}$ & $\begin{array}{c}0.308917 \\
(0.569980)\end{array}$ & $\begin{array}{c}1.731423 \\
(10.227577)\end{array}$ & $\begin{array}{c}0.315316 \\
(0.322510)\end{array}$ \\
\hline G & $\begin{array}{c}-0.751904 * * * \\
(0.165716)\end{array}$ & $\begin{array}{c}1.894814 \\
(1.935104)\end{array}$ & $\begin{array}{c}-0.253343^{* *} \\
(0.103181)\end{array}$ \\
\hline $\mathrm{H}$ & $\begin{array}{c}-1.187265^{* *} \\
(0.485049)\end{array}$ & $\begin{array}{c}1.449605 \\
(2.839533)\end{array}$ & $\begin{array}{c}0.014257 \\
(0.294980)\end{array}$ \\
\hline $\mathrm{S}$ & $\begin{array}{l}-3.839335 \\
(2.553237)\end{array}$ & $\begin{array}{c}4.444026 \\
(16.120303)\end{array}$ & $\begin{array}{c}-0.196096 \\
(1.525899)\end{array}$ \\
\hline
\end{tabular}

Adding the control variables to the regression of the fixed effects model, Table 3 shows that for the entire urban agglomeration, central cities and surrounding cities, the impact coefficient of the secondary industry scale on the energy consumption per unit of GDP is still significantly negative, indicating that the scale of the secondary industry affects the energy consumption per unit of GDP. The reduction in consumption plays a significant role in promoting.

\subsubsection{The influence of control variables on energy efficiency}

The impact of industrial agglomeration on the overall urban agglomeration is significantly negative at the level of $1 \%$, indicating that industrial agglomeration plays a significant role in the reduction of unit GDP energy consumption in urban agglomerations. Its impact is significant for surrounding cities, but not for central cities. Significantly.

The industrial structure has no significant impact on the overall urban agglomeration, central cities and surrounding cities. The main reason is that the secondary and tertiary industries in the Chengdu-Chongqing urban agglomeration are in a rapid development stage, and there is little difference in the industrial structure of different cities.

Government intervention has a significant negative impact on the urban agglomerations as a whole at the $1 \%$ level, indicating that government intervention has played a significant role in reducing the energy consumption per unit of GDP in urban agglomerations, and its impact is significant for surrounding cities, but not for central cities. Significantly. It shows that the influence of government intervention in surrounding cities is greater than that of central cities. 
Human capital has a significant negative impact on the overall urban spillover agglomeration at the level of 5\%, indicating that human capital has a significant role in promoting the reduction of energy consumption per unit of GDP in urban agglomerations. According to the classification of central cities and surrounding cities, the impact both are not significant. The main reason is that the level of investment in education is not directly related to the level of the city.

The innovation level has no significant impact on the overall urban agglomeration, central cities, and surrounding cities. The main reason is that the proportion of science and technology expenditures in fiscal expenditures in the Chengdu-Chongqing urban agglomeration from 2010 to 2015 is small. The regional gap is obvious. Taking 2015 as an example, the ChengduChongqing urban agglomeration's science and technology expenditures accounted for the largest proportion of fiscal expenditures in Chengdu 2.66\%, while Beijing's 5.02\%, Shanghai's $4.39 \%$, and the province's average of $4.65 \%$.

\subsection{Robustness test}

In order to ensure the robustness of the regression results, this study uses the log value of the secondary industry's employment population instead of the secondary industry's regional GDP for robustness test. The test results are shown in Table 4.

Table 4. Robustness test results

\begin{tabular}{|c|c|c|c|}
\hline variable & $\begin{array}{c}\text { Urban } \\
\text { agglomeration }\end{array}$ & central city & Nearby Cities \\
\hline I & $\begin{array}{c}-0.65705^{* * *} \\
(0.17847)\end{array}$ & $\begin{array}{c}-2.11563 * * * \\
(0.44857)\end{array}$ & $\begin{array}{c}-0.43547 * * \\
(0.17805)\end{array}$ \\
\hline $\mathrm{D}$ & $\begin{array}{c}-0.53208^{* * *} \\
(0.14050)\end{array}$ & $\begin{array}{l}-1.04281 \\
(0.81874)\end{array}$ & $\begin{array}{c}-0.51879 * * * \\
(0.13776)\end{array}$ \\
\hline $\mathrm{C}$ & $\begin{array}{c}0.64062 \\
(0.66023)\end{array}$ & $\begin{array}{c}-0.61904 \\
(7.97110)\end{array}$ & $\begin{array}{c}0.90013 \\
(0.63758) \\
\end{array}$ \\
\hline G & $\begin{array}{c}-0.79525^{* * *} \\
(0.19269)\end{array}$ & $\begin{array}{c}2.32099 \\
(1.48757)\end{array}$ & $\begin{array}{c}-0.86021 * * * \\
(0.18392)\end{array}$ \\
\hline $\mathrm{H}$ & $\begin{array}{c}-1.27555^{* *} \\
(0.56475) \\
\end{array}$ & $\begin{array}{r}1.01839 \\
(2.20052) \\
\end{array}$ & $\begin{array}{c}-1.22064^{* *} \\
(0.55660)\end{array}$ \\
\hline $\mathrm{S}$ & $\begin{array}{l}-4.01658 \\
(3.04261)\end{array}$ & $\begin{array}{c}7.38450 \\
(12.51654)\end{array}$ & $\begin{array}{l}-5.20409 * \\
(2.99670)\end{array}$ \\
\hline
\end{tabular}

Note: *** means $\mathrm{p}<0.01, * *$ means $\mathrm{p}<0.05, *$ means $\mathrm{p}<0.1$, standard error in parentheses

For the entire urban agglomeration, central cities and surrounding cities, the influence coefficient of the employment population of the secondary industry on the energy consumption per unit of GDP is still significantly negative, indicating that the scale of the secondary industry has played a significant role in promoting the reduction of energy consumption per unit of GDP. Therefore, the foregoing conclusion is robust.

\subsection{Endogenous test}

In the process of urban industry development, the government has more financial resources to intervene in the economy, attract high-tech talents, and improve the level of innovation, which may cause endogenous problems. This study lags behind government intervention, human capital, and innovation level among the control variables 1 The period replaces the current variables and has sufficient exogeneity. Table 5 shows that for the overall urban agglomeration, central cities and surrounding cities, the coefficient relationship and significance of the secondary industry scale to unit GDP energy consumption have not changed.

Table 5. The control variable lags the measurement result by one period

\begin{tabular}{|c|c|c|c|}
\hline variable & $\begin{array}{c}\text { Urban } \\
\text { agglomeration }\end{array}$ & central city & Nearby Cities \\
\hline \multirow{2}{*}{ I } & $\begin{array}{c}-0.124639 * * * \\
(0.023668)\end{array}$ & $\begin{array}{c}-0.108812 * * \\
(0.025121)\end{array}$ & $\begin{array}{c}-0.836501 * * * \\
(0.061620)\end{array}$ \\
\hline \multirow{2}{*}{$\mathrm{D}$} & $\begin{array}{c}-0.115799 \\
(0.092232)\end{array}$ & $\begin{array}{c}0.856789 \\
(0.633162)\end{array}$ & $\begin{array}{c}-0.076435 \\
(0.049800)\end{array}$ \\
\hline \multirow{2}{*}{$\mathrm{C}$} & $\begin{array}{c}1.489880 * * \\
(0.655272)\end{array}$ & $\begin{array}{c}3.295618 \\
(5.306086)\end{array}$ & $\begin{array}{c}-0.201425 \\
(0.385572)\end{array}$ \\
\hline \multirow{2}{*}{ L.G } & $\begin{array}{c}-0.618551 * * * \\
(0.155135)\end{array}$ & $\begin{array}{c}-0.442993 \\
(1.150542)\end{array}$ & $\begin{array}{c}-0.164126 * \\
(0.088270)\end{array}$ \\
\hline \multirow{2}{*}{ L.H } & $-0.968829 * *$ \\
& $(0.434882)$ & -2.450391 & 0.299009 \\
\hline \multirow{2}{*}{ L.S } & $-5.814619 * *$ & 21.598969 & -0.614676 \\
& $(2.537984)$ & $(13.515998)$ & $(1.384385)$ \\
\hline
\end{tabular}

Note: $* * *$ means $\mathrm{p}<0.01, * *$ means $\mathrm{p}<0.05, *$ means $\mathrm{p}<0.1$, standard error in parentheses

\section{Conclusions and recommendations}

In the context of increasing attention to environmental protection, exploring the relationship between industrial development and energy consumption in urban agglomerations is of great significance for improving the land and space environment and achieving high-quality development. The following conclusions are mainly obtained through this research.

(1) Industrial development forms large-scale production, which will increase the total energy consumption, but it also contributes to the improvement of energy utilization efficiency. Industrial development and energy efficiency improvement are complementary and positively correlated, and ecological protection should be sought during development.

(2) Urban agglomerations in the rapid development stage have basically the same impact on energy efficiency of different urban industrial structures, and the degree of impact is not significant.

(3) From the analysis of the data, it can be found that government intervention has a greater impact on industrial development and the improvement of energy efficiency. The influence of government intervention in surrounding cities is greater than that of central cities.

(4) The level of investment in education is not directly related to the level of the city, and the proportion of science and technology expenditures in fiscal expenditures is not much different between cities, and needs to be further improved. 


\section{References}

1. Yan Yin-gen, Wen Yang. (2017) Could the Planning of Urban Agglomeration Promote Regional Industrial Development? -Based on New Geographical Economics. Economic Survey, 34(02): 1-6.

2. Zang Chuan qin, Liu Yan. (2012) Analysis on Total Factor Energy Efficiency and Its Influencing Factors of Shandong Thinking about Environmental Pollution. China Population, Resources and Environment, 22(08):107-113.

3. Xu Cheng bin. (2020) A study on China's energy development and its economic efficiency. Macroeconomic Management, 06: 51-60.

4. Zhao Yong, Wei Houkai. (2015) The Government Intervention, the Division of labor of the Function of the Space of the City Group, and the Difference in District: On the Effectiveness of Regional Policy in China. Management World. Management World, 08: 14-29+187.

5. $\mathrm{Xu}$ De,Chen Congjian. (2020) Research on the Improvement of the Innovate Urban Primacy Index in Central Cities: Case Study of Nanjing Metropolitan Area. Modern Urban Research, 12: 126-131.

6. Shang Yongzhen,Chen Yao. (2020) Does the Functional Division in Urban Agglomerations Contribute to Economic Growth?-An Empirical Research Based on Panel Data of Top Ten Urban Agglomerations. Economic Survey, 37(01) : 1-8.

7. J. A. Hausman. (1978) Specification Tests in Econometrics. Econometrica,46(6) : 1251 - 1271.

8. J. A. Hausman, W.E. Taylor. (1981) Panel Data and Unobservable Individual Effects. Econometrica, 49(6) : 1377-1398. 